Japan. J. Med. Sci. Biol., 29, 139-150, 1976

\title{
A NEW BIOLOGICAL ASSAY METHOD FOR HISTAMINE- SENSITIZING FACTOR USING SURVIVAL TIME AS A RESPONSE
}

\author{
Setsuji ISHIDA, Masami KUROKAWA and Sadao ASAKAWA \\ Department of General Biologics Control, National Institute of Health, \\ Kamiosaki, Shinagawa-ku, Tokyo 141, Japan
}

(Received: February 23, 1976)

\begin{abstract}
SUMMARY: A new biological assay method using survival time of mice as a graded response after histamine challenge has been developed for the histaminesensitizing factor of pertussis bacilli. The method is relatively precise and reproducible in estimation and fairly sensitive in the validity tests of biological assay.

Effect of endotoxin on the estimation by the proposed method was also investigated in case the method is applied to the control test of pertussis vaccine.
\end{abstract}

\section{INTRODUCTION}

For quantitative determination of the histamine-sensitizing factor (HSF) or histamine-sensitizing (HS) activity of products of pertussis bacilli, the assay method using lethality of mice as a response has widely and exclusively been adopted since Pittman (1951a, b).

The log dose-quantal response regression is relatively flat and considerably many mice are required for precise and reproducible estimation of the factor. A graded response would be preferred to the lethality, since the former provides a method enabling more precise and reproducible estimation with relatively few animals. However, there has been no report along this line.

We found a certain correlation between the mean survival time after challenge with histamine and the dose of the material used for sensitization of mice. Based on this finding and on the principle of parallel line assay, a new biological assay method was developed for quantitative determination of HSF.

Since an HS activity of bacterial endotoxin has been reported (Kuratsuka et al., 1975) though the effective dose is very small, endotoxin may affect the HS activity of a pertussis vaccine. Therefore, effect of endotoxin on the estimation by this method was also investigated.

The present report describes the experimental results, from which the method was developed.

石田説而・黒川正身・朝川貞雄（国立予防衛生研究所 一般検定部） 


\section{Materials ANd Methods}

$D P$ and DPT vaccine: A diphtheria-pertussis-tetanus combined (DPT) vaccine, $T-11$, was selected as a tentative intralaboratory reference preparation from DPT and diphtheria-pertussis combined (DP) vaccines submitted to the National Institute of Health for the national control tests, as it contained relatively high HS and lymphocytosis-promoting (LP) activities.

Dutch Reference Pertussis Vaccine (RIV) was supplied by courtesy of Dr. J. D. van Rhamshorst, Rijks Instituut voor de Volksgesondheid, Bilthoven, the Netherlands. One milliliter of the material reconstituted according to the attached direction was due to contain 3 International Mouse Protective Units and 3 HS units (HSU, Pittman, 1975). A comparative test of T-11 and RIV for HSF by the proposed method showed that T-11 contained about $3.3 \mathrm{HSU} / \mathrm{ml}$ (see Fig. 4).

The endotoxin contents of the two vaccines were nearly the equal when measured by the assay method using leukocytic response in mice as a response (Kurokawa et al., 1974), and roughly corresponds to the mean endotoxin content of all DP and DPT vaccines recently produced in Japan (Ishida et al., unpublished data).

Other DP and DPT vaccines used in the present experiment were those submitted to the Institute for the national control tests. The descriptions of these vaccines will be given at the places concerned, if necessary.

LPF preparation: Partially purified LPF preparations, F234 and F201, were supplied by Dr. S. Iwasa. The processes of preparation and their biological properties were almost the same as those described in our previous paper (Kurokawa et al., 1974). They had little toxic activity attributable to endotoxin and fairly strong HS activity in addition to LP activity. Their HS activities were estimated by the proposed method to be both about $0.2 \mathrm{HSU} / \mu \mathrm{g}$ (see p. 144).

Histamine solution: Histamine hydrochloride (Sigma Chemical Co., St. Louis, Mo.) was dissolved in physiological saline to a concentration of $4 \mathrm{mg} / 0.5 \mathrm{ml}$.

Mice: The source, quarantine and assignment of mice were the same as described in our previous report (Kurokawa et al., 1974). Ten mice were used for each dose. When not all mice succumbed to histamine challenge, means and their variances were calculated from the data obtained with less than 10 mice.

Experimental methods: Materials serially diluted in physiological saline were injected intraperitoneally into mice in volumes of $0.5 \mathrm{ml}$. On the fourth day after injection, the mice were challenged intraperitoneally with 0.5 -ml volumes of the histamine solution. The survival time in minutes of each animal was recorded. When many mice were to be injected in one experiment, the injection of histamine solution was carried out every $30 \mathrm{sec}$ to avoid possible confusion in recording the survival times.

Statistical analysis: Regression analyses and parallel line assays were carried out according to Finney's method (1964). Significance and validity tests were made at a probability $(\mathrm{p}=0.05)$ and confidence intervals were expressed at $95 \%$ probability level unless otherwise stated. 


\section{RESULTS}

\section{Response Metameter}

Most mice sensitized with T-11 died between 10 and 24 min after histamine challenge; the survival time was dependent on the dose of a test material (Fig. 1). Though nonlinearity of the regression of the response versus log dose was not significant before logarithmic transformation of the response, the variance depended on the mean before the transformation; the larger the mean, the larger the confidence interval. This dose dependency of variance disappeared after the logarithmic transformation of the survival time.

In Fig. 2, individual variances for assay data with $36 \mathrm{DP}$ and $3 \mathrm{DPT}$ vaccines were plotted against the corresponding means. The variance depended on the mean before log transformation (Fig. 2a), while there was little correlation between them after the transformation (Fig. 2b).

These results clearly show that the logarithms meet the criteria for a response

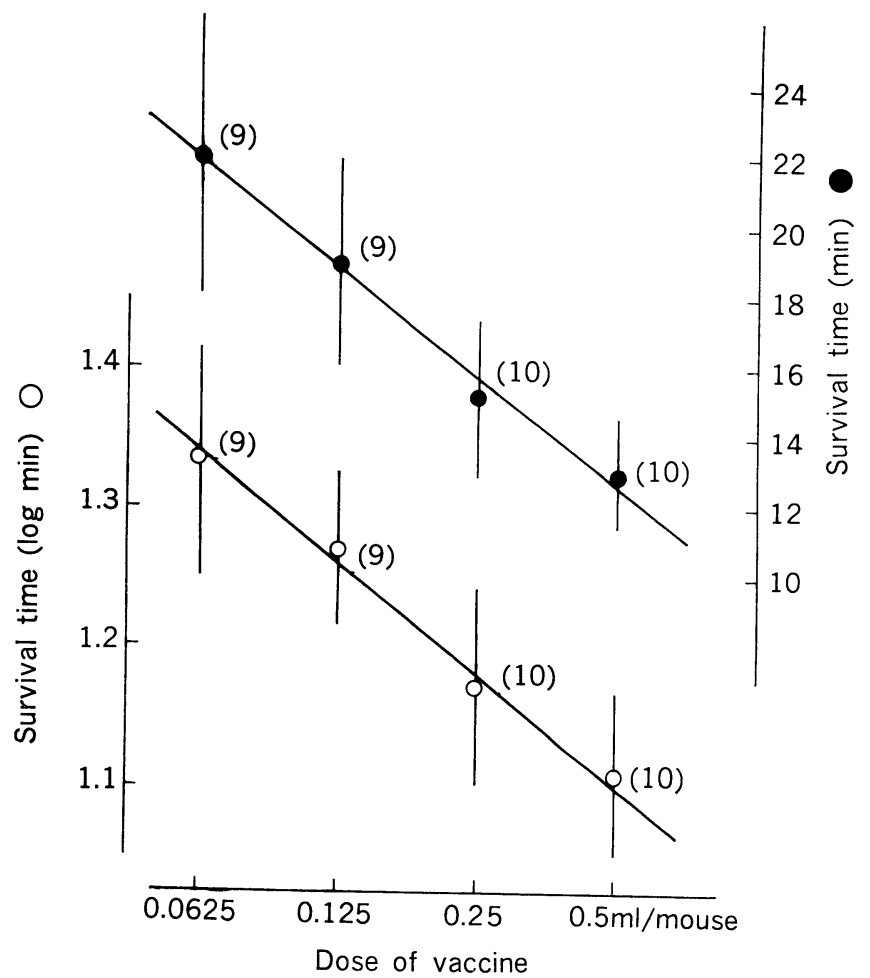

Fig. 1. Dose-response regressions for a DPT vaccine.

Material: T-11

Closed and open circles represent arithmetic (๑) and log-geometric (O) means of survival times in minutes, respectively. The figure in parentheses represents number of mice per dose. The vertical bar indicates the confidence interval of the mean. 

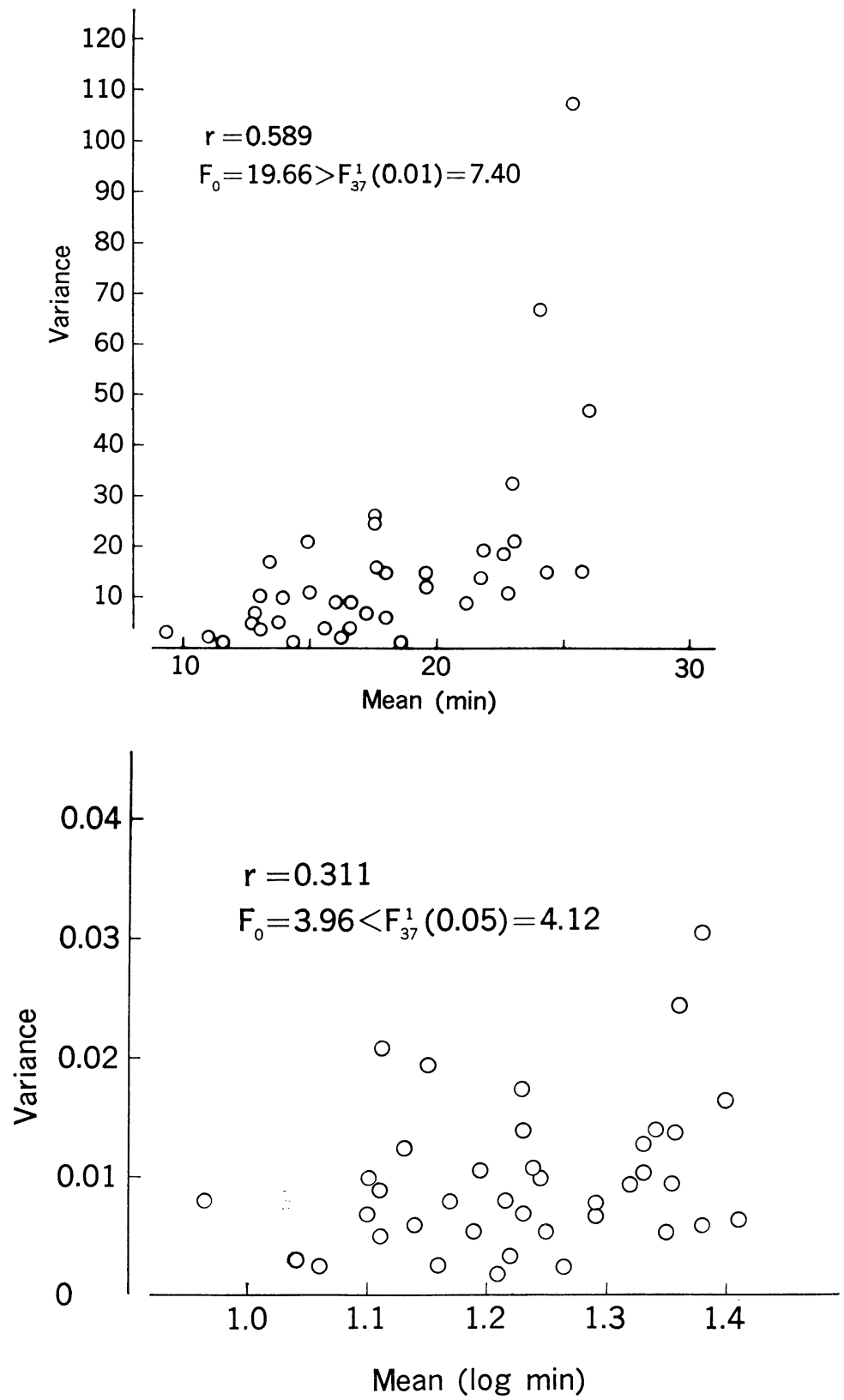

Fig. 2. Correlation between individual mean $\log$ minutes and variances. Materials: $39 \mathrm{DP}$ and DPT vaccines submitted to the National Institute of Health for the national control tests.

2a: individual variances vs. individual arithmetic means. $2 \mathrm{~b}$ : individual variances vs. individual log-geometric means. $\mathrm{r}$ : correlation coefficient; $F_{0}$ : observed $F$ value; $F_{37}^{1}(0.01)$, $\mathrm{F}_{37}(0.05): \mathrm{F}$ value at $\mathrm{p}=0.01$ or $\mathrm{p}=0.05$ with 1 and 37 degrees of freedom. 
metameter. Hereafter survival time in minutes transformed to logarithm was used as a response for statistical analysis.

\section{Dose-response Regression and Common Statistics}

T-11 was assayed eight times each with 3 to 4 doses and 10 mice per dose. Though the regression coefficients varied from -0.212 to -0.564 (Table I), deviations from parallelism by the eight regression lines obtained were not significant, showing consistency of the regression coefficient. A common regression coefficient was -0.342 , and a common variance 0.0078 (Table I).

TABLE I

Regression coefficients and confidence intervals for 8 trials with $T-11$

\begin{tabular}{|c|c|c|c|}
\hline \multicolumn{3}{|c|}{ Regression coefficient } & Confidence interval \\
\hline 1 & -0.268 & & $-0.401,-0.136$ \\
\hline 2 & -0.367 & & $-0.504,-0.230$ \\
\hline 3 & -0.212 & & $-0.357,-0.068$ \\
\hline 4 & -0.513 & & $-0.689,-0.337$ \\
\hline 5 & -0.341 & & $-0.535,-0.147$ \\
\hline 6 & -0.564 & & $-0.928,-0.200$ \\
\hline 7 & -0.355 & & $-0.528,-0.181$ \\
\hline 8 & -0.368 & & $-0.514,-0.223$ \\
\hline Common & -0.342 & & $-0.398,-0.286$ \\
\hline Nature of variation & SS & $\mathrm{df}$ & MS \\
\hline Parallelism & 0.0760 & 7 & 0.0109 \\
\hline Error & 1.0910 & 139 & 0.0078 \\
\hline Total & 1.1670 & & \\
\hline
\end{tabular}

Parallelism among regression lines of different DPT vaccines was also tested. Figure 3 is an example, in which two vaccines were compared with T-11. The three vaccines were produced by different manufacturers in Japan. There was no indication for deviation from parallelism in this experiment (see the table attached to the figure). The HS activity of KI was almost the same as that of $\mathrm{T}-11$, while that of $\mathrm{KA}$ was nearly half that of $\mathrm{T}-11$.

To estimate the relative HS activity of the reference preparation to RIV, an experiment was designed as presented in Fig. 4. No significant deviation from parallelism was demonstrated between the two regressions. The HS activity of $\mathrm{T}-11$ was estimated to be $3.3 \mathrm{HSU} / \mathrm{ml}$ with $95 \%$ confidence limmits of 0.9 and 5.4 HSU.

\section{Effect of Endotoxin on the Regression Line of HSF}

A series of experiments were carried out to examine the possible effect of 


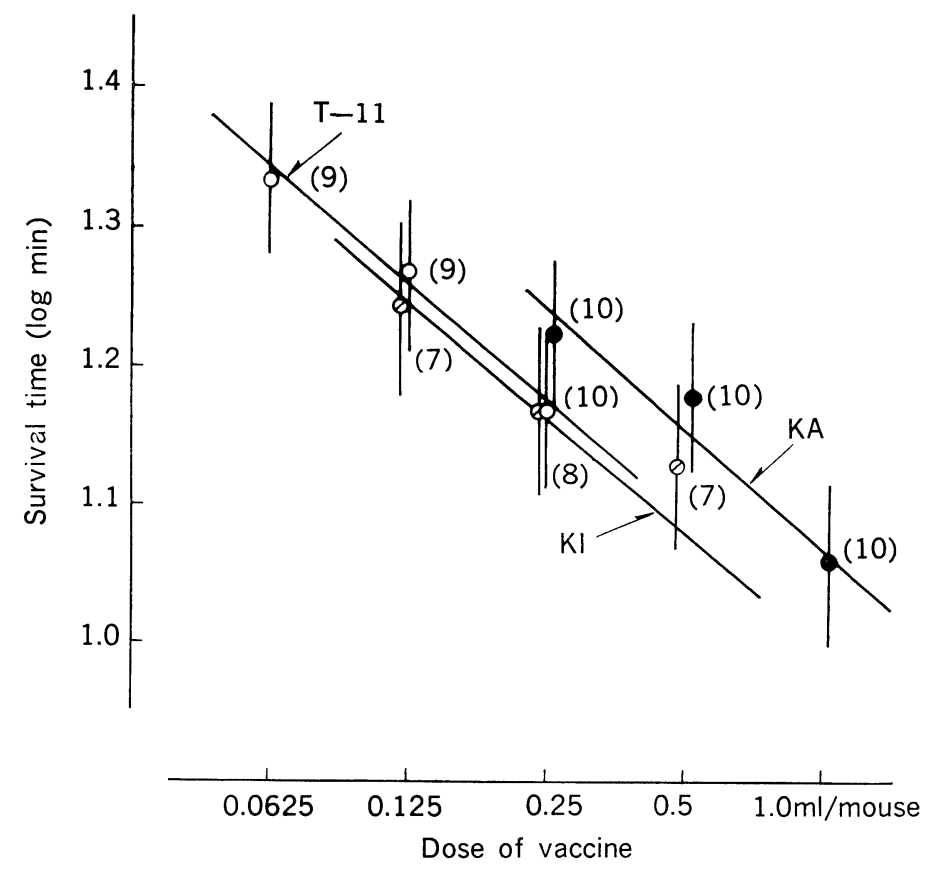

Fig. 3. Dose-response regressions for three DPT vaccines.

Materials: T-11, KI and KA. The three vaccines were produced by three different manufacturers.

For the vertical bars and figures in parentheses, see the legends for Fig. 1.

Variance analysis for the data presented in Fig. 3

\begin{tabular}{lcrrr}
\hline Nature of variation & SS & df & \multicolumn{1}{c}{ MS } & \multicolumn{1}{c}{ F } \\
\hline Preparations & 0.1490 & 2 & 0.0745 & 9.92 \\
Regression & 0.2856 & 1 & 0.2056 & 39.35 \\
Parallelism & 0.0069 & 2 & 0.0034 & \\
Linearity & 0.0129 & 3 & 0.0043 & \\
\hline Between doses & 0.4643 & 8 & 0.0580 & \\
Error & 0.5334 & 71 & 0.0075 & \\
\hline Total & 0.9977 & 79 & &
\end{tabular}

endotoxin on the regression of HSF in case of a comparative toxicity test of DP and DPT vaccines, which inevitably contain endotoxin.

In Fig. 5, T-11 and F234 were tested for parallelism between regression lines. The regression coefficient of the line of the HS activity of the LPF preparation showed no significant difference from that of T-11. As the LPF preparation was proven to contain little endotoxin, the result seemed to suggest that endotoxin contained by $\mathrm{T}-11$ had only a little effect, if any, on the regression of HSF.

By using mixtures of F201 and WE-1, the possible effect of endotoxin on HS 


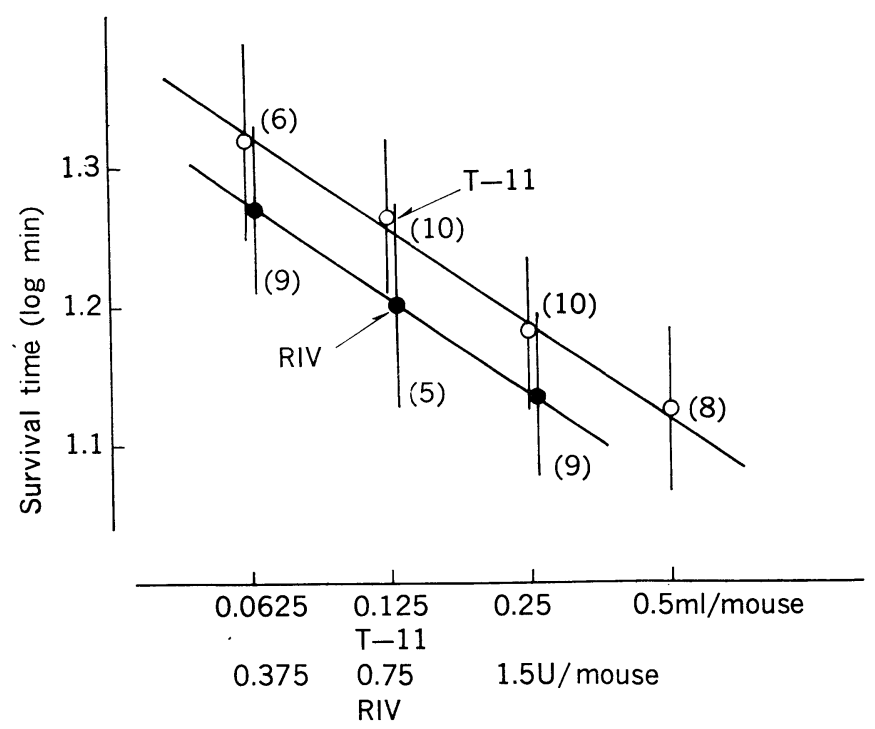

Fig. 4. Estimation of the relative HS activity of T-11 to RIV. Materials: T-11 and RIV

For the circles, vertical bars and figure in parentheses, see the legends for Figs. 1 and 3.

Variance analysis for the data presented in Fig. 4

\begin{tabular}{|c|c|c|c|c|c|c|c|}
\hline \multicolumn{2}{|c|}{ Nature of variation } & SS & & $\mathrm{df}$ & & MS & $\mathbf{F}$ \\
\hline \multicolumn{2}{|c|}{ Preparations } & 0.0041 & & 1 & & 0.0041 & 0.58 \\
\hline \multicolumn{2}{|c|}{ Regression } & 0.2440 & & 1 & & 0.2440 & 34.47 \\
\hline \multicolumn{2}{|c|}{ Parallelism } & 0.0000 & & 1 & & 0.0000 & \\
\hline \multicolumn{2}{|c|}{ Linearity } & 0.0023 & & 3 & & 0.0008 & 0.11 \\
\hline \multicolumn{2}{|c|}{ Between doses } & 0.2504 & & 6 & & 0.0417 & \\
\hline \multicolumn{2}{|c|}{ Error } & 0.3539 & & 50 & & 0.0071 & \\
\hline \multirow[t]{2}{*}{ Total } & & 0.6043 & & 56 & & & \\
\hline & \multicolumn{2}{|c|}{ Relative toxicity } & \multicolumn{5}{|c|}{ Fiducial limits } \\
\hline RIV & \multicolumn{2}{|c|}{$1.0(3.0 \mathrm{U} / \mathrm{ml})$} & & & \multirow{2}{*}{\multicolumn{2}{|c|}{$\mathrm{U} / \mathrm{ml}), 1.8$}} & \\
\hline $\mathrm{T}-11$ & 1.1 & $\mathrm{U} / \mathrm{ml})$ & 0.3 & $(0.9$ & & & $\mathrm{U} / \mathrm{ml})$ \\
\hline
\end{tabular}

activity was investigated. Each of three graded doses of F201 and of WE-1 were mixed to make nine combinations. Nine means of log survival times were plotted against the combinations of the doses of endotoxin and F201 to make a doseresponse regression grid. In Fig. 6, a regression line of HS activity alone without possible effect of endotoxin is also presented for comparison.

The lines sloping down from left to right are the regressions of log survival time versus log dose of F201 at three constant doses of endotoxin, and those sloping up from left to right the regressions of endotoxin at three constant doses of F201. The former three lines were parallel one another and a common regres- 


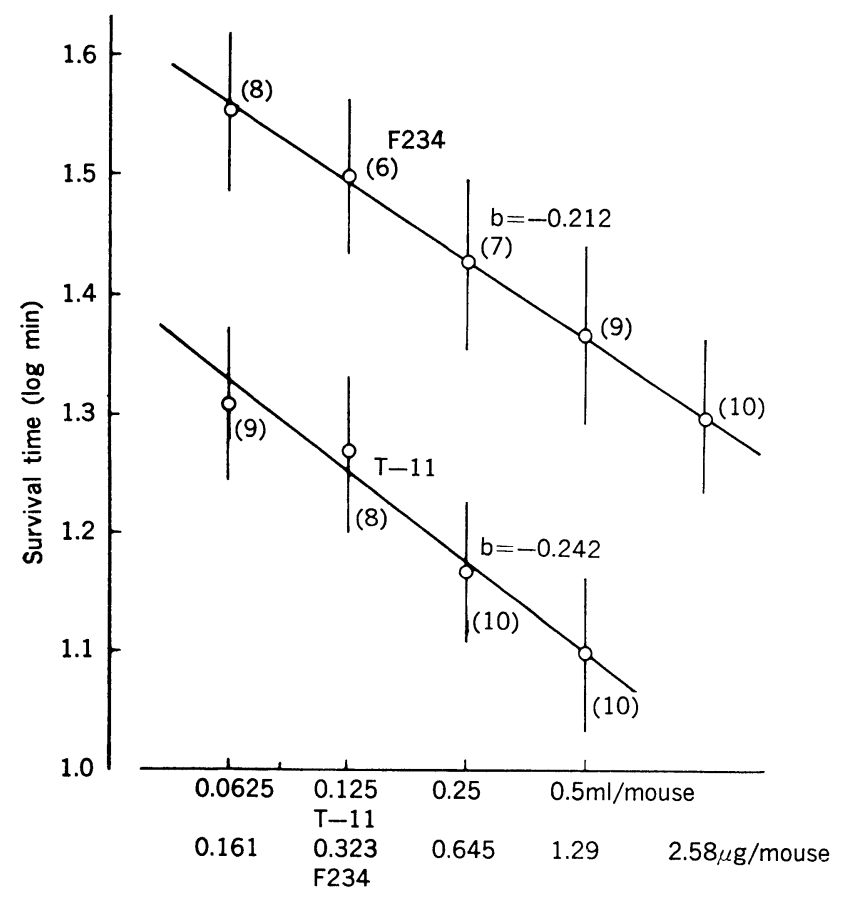

Fig. 5. Parallelism between dose-response regressions for T-11 and an LPF preparation. Materials: T-11 and F-234

For the circles, bars and figures in parentheses, see the legends for Figs. 1 and 3.

Variance analysis for the data presented in Fig. 5

\begin{tabular}{lcrcc}
\hline Nature of variation & SS & df & MS & F \\
\hline Preparations & 0.8702 & 1 & 0.8702 & 86.5 \\
Regression & 0.6094 & 1 & 0.6094 & 60.6 \\
Parallelism & 0.0026 & 1 & 0.0026 & \\
Linearity & 0.0077 & 5 & 0.0015 & \\
\hline Between doses & 1.4900 & 8 & 0.1863 & \\
Error & 0.6942 & 69 & 0.0101 & \\
\hline Total & 2.1842 & 77 & &
\end{tabular}

sion coefficient was -0.376 , significantly different from that of F201 alone. The latter three lines were also parallel one another and a common regression coefficient was fairly flat but the regression of endotoxin was significant (table attached to the Fig. 6).

The following equation giving the mean log survival time (y) after histamine challenge as functions of the log dose of endotoxin $\left(\mathrm{x}_{1}\right)$ and F201 $\left(\mathrm{x}_{2}\right)$ furnishes the slopes and the intercept for evaluating the coefficient of the equation.

$$
\mathrm{y}=1.458+0.105 \mathrm{x}_{1}-0.376 \mathrm{x}_{2}
$$




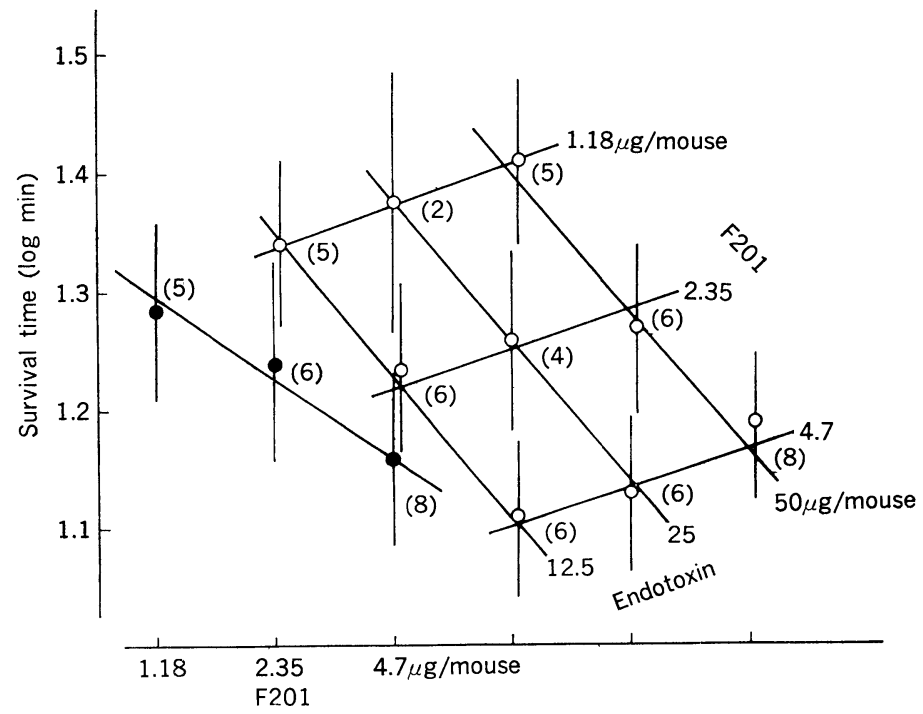

Fig. 6. Dose-response regression grid made with endotoxin and LPF.

Materials: WE-1 and F201

The open circle represents a mean response of about 10 mice per combination of endotoxin and LPF.

The closed circle indicates a mean response to LPF alone. For the bars and figures in parentheses, see the legend for Fig. 1.

Variance analysis for the data presented in Fig. 6

\begin{tabular}{lcccr}
\hline Nature of variation & SS & df & MS & F \\
\hline Regression of F201 & 0.2878 & 4 & 0.2878 & 62.5 \\
$\begin{array}{l}\text { Regression of } \\
\quad \text { endotoxin }\end{array}$ & 0.0298 & 1 & 0.0298 & 4.7 \\
Residual & 0.2715 & 44 & 0.0062 & \\
\hline
\end{tabular}

Total

0.6886

The theoretical survival time was calculated by inserting the doses of F201 and endotoxin used in the experiment in Fig. 6 into the above equation (1) and plotted against the experimentally observed data to make a fairly straight line (Fig. 7). Relative toxicities of mixtures of F201 and 12.5, 25 or $50 \mu \mathrm{g}$ of WE-1 to that of F201 alone were calculated to be 1.015, 0.906 and 0.659 , respectively. Though the differences were not significant, it seemed that the HS activity decreases as endotoxin content increases.

In the experiments presented above, dose of either F201 or endotoxin was varied while that of the other material was kept constant. In the next experiment, a mixture containing $50 \mu \mathrm{g}$ of WE-1 and $4.7 \mu \mathrm{g}$ of F201 per ml was serially diluted so that the ratios of the two components were kept constant (Fig. 8). Though neither significant deviation from parallelism nor significant difference in the HS activity was demonstrated between F201 alone and the mixture of 


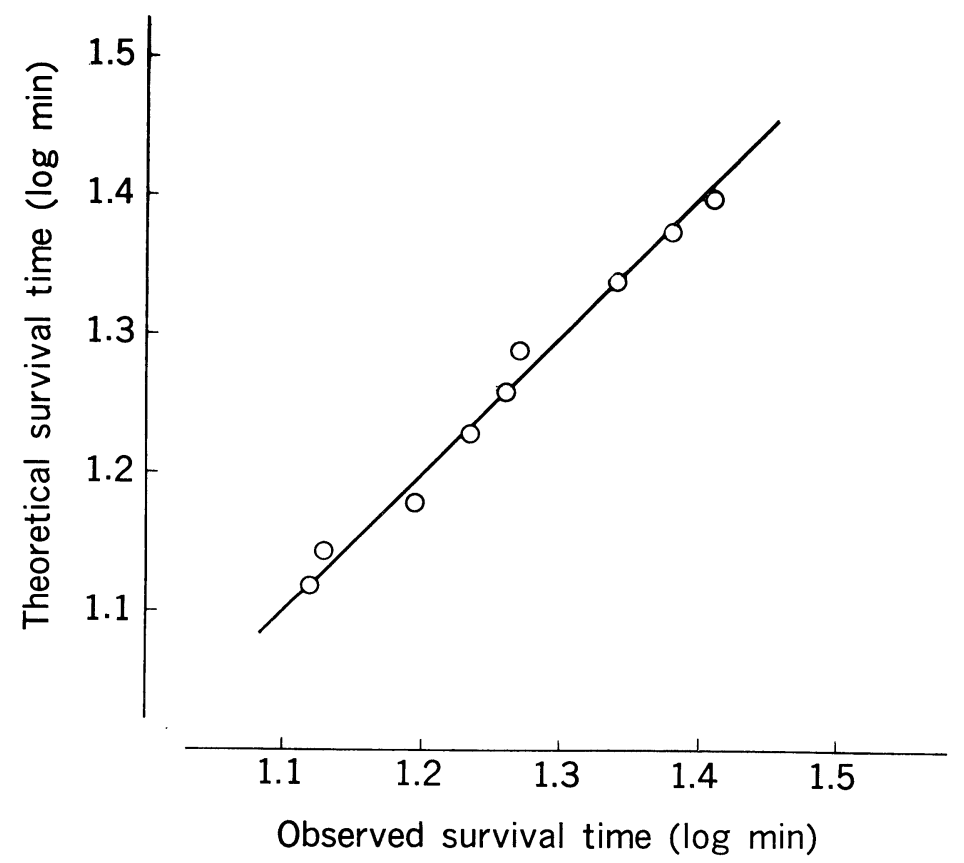

Fig. 7. Correlation between theoretical and observed survival times. Theoretical survival time was calculated by equation (1) in the text.

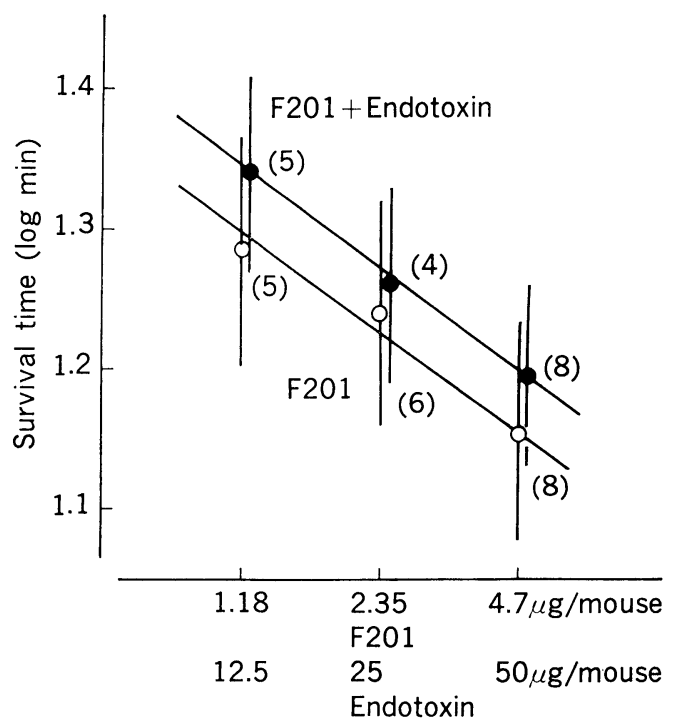

Fig. 8. Dose-response regressions of a mixture of endotoxin and LPF and LPF alone. For the circles, bars and figures in parentheses, see the legends for Figs. 1 and 3. 
endotoxin and F201, the regression line of the HS activity tended to move somewhat upward by the addition of endotoxin.

\section{Discussion}

Generally speaking, a biological assay method based upon a graded response, if possible, is preferable to that based upon a quantal response, since the former usually provides more information for statistical analyses; with the same number of animals, the former may allow more precise estimates than the latter, or for the same level of precision of estimation, the former requires fewer animals than does the latter.

As an example, a confidence interval of $\mathrm{HSD}_{50}$ was calculated from the results reported by Preston (1959) by the probit method to compare with that of a mean dose estimated by the proposed method. The data obtained by individual experiments with vaccine B in Table IV of Preston's paper except those with the lowest two doses were combined and used for the calculation, since they were relatively satisfactory in respect of linearity of the regression and steepness of the slope. The confidence interval of $\mathrm{HSD}_{50}$ of vaccine $\mathrm{B}$ was 0.13 in logarithms to base 10 with a sample size of about 260 . The method proposed in the present paper would give a similar confidence interval with about 100 mice, if the design of experiment is suitable. With vaccine $A$ in Table IV of Preston's paper, as the theoretical variance can not be used in the calculation of fiducial interval because of the significant deviation from linearity, the precision of estimate considerably decreases.

The new assay method proposed in this paper was developed along the principle mentioned above. The survival time after histamine challenge could be employed as a graded response. The log transformation of the survival time was adopted based on the test for the homogeneity of variances. The criteria for normal distribution were not directly tested, for there have been a lot of reports in the field of biological assay showing that log survival or latent time is normally distributed and that plotting the log response time against the log dose gives a straight one (e.g. Gaddum, 1953). Besides, the biological meaning of low normal distribution of response time has been discussed by several authors (e.g. Uetake, 1957; Meynell, 1963).

The deaths of mice occur in such a narrow range of time after histamine challenge that some device may be necessary to record the exact survival time of each of many mice subjected to one experiment. One of such procedures used by us was presented.

To economize mice, the doses of inocula should be within such a range that the resulting log dose-log response line is linear and the smallest dose should be sufficient to sensitize mice so that no mouse would survive the challenge with histamine. Then, most mice used in the experiment would provide information for the estimation.

The present experiments suggest that endotoxin affects the dose response 
regression of $\mathrm{HSF}$ in both the slope and the intercept, though in most cases significance tests gave negative results. Therefore, comparative assay by the method proposed here can safely be used with preparations whose endotoxin contents are within a limited range. Endotoxin contents of most of DP and DPT vaccines produced in Japan were found by peripheral leukocytic response in mice (Kurokawa et al., 1974) to range from about 50 to $200 \mu \mathrm{g} / \mathrm{ml}$, being equivalent to the weight of WE-1 used as a reference preparation of endotoxin (Ishida et al., unpublished data). Therefore, by selecting an appropriate reference preparation of DP or DPT vaccine containing endotoxin at a concentration of $100 \mu \mathrm{g} / \mathrm{ml}$ or so in terms of WE-1, a comparative assay will be applicable to any DP or DPT vaccines normally available.

It was reported that endotoxin itself showed an HS activity and affected the HS activity of the product of pertussis bacilli when determined by lethality of sensitized mice after histamine challenge (Kuratsuka et al., 1975). The amounts of endotoxin used in the present experiment were much larger than those used by them.

\section{ACKNOWLEDGeMent}

The authors wish to express their thanks to Dr. D. J. van Ramshorst, Bilthoven, the Netherlands, for the supply of the Netherlands Reference Pertussis Vaccine.

\section{REFERENCES}

Finney, D. J. (1964): Statistical Method in Biological Assay. 2nd ed., Charles Griffin, London. Gaddum, J. H. (1953): Bioassays and mathematics. Pharmacol. Rev., 5, 87-134.

Kuratsuka, K., Homma, R., Shimazaki, Y. and Funasaka, I. (1975): Rapid appearance of histamine hypersensitivity in mice by minute dose of endotoxins. Experientia, 31, 206-208.

Kurokawa, M., Ishida, S., Goto, N. ANd Kuratsuka, K. (1974): A new method for biological assay of endotoxin using change in peripheral leukocyte population in mice as a response. Japan. J. Med. Sci. Biol., 27, 173-189.

Meynell, G. G. (1963): Interpretation of distributions of individual response times in microbial infections. Nature, 198, 970-973.

Pittman, M. (1951a): Influence of sex of mice on histamine sensitivity and protection against Hemophilus pertussis. J. Infect. Dis., 89, 296-299.

Pittman, M. (1951b): Comparison of the histamine-sensitizing property with the protective activity of pertussis vaccines for mice. J. Infect. Dis., 89, 300-304.

Pittman, M. (1975): Determination of the histamine sensitizing unitage of pertussis vaccine. J. Biol. Standard., 3, 185-191.

Preston, N. W. (1959): Factors influencing the assay of the histamine-sensitizing factor of Haemophilus pertussis. J. Pathol. Bacteriol., 78, 217-224.

Uetake, H. AND Nakagawa, T. (1957): Distributions of individual survival times in animal experiments. Japan. J. Bacteriol., 12, 23-26 (text in Japanese). 